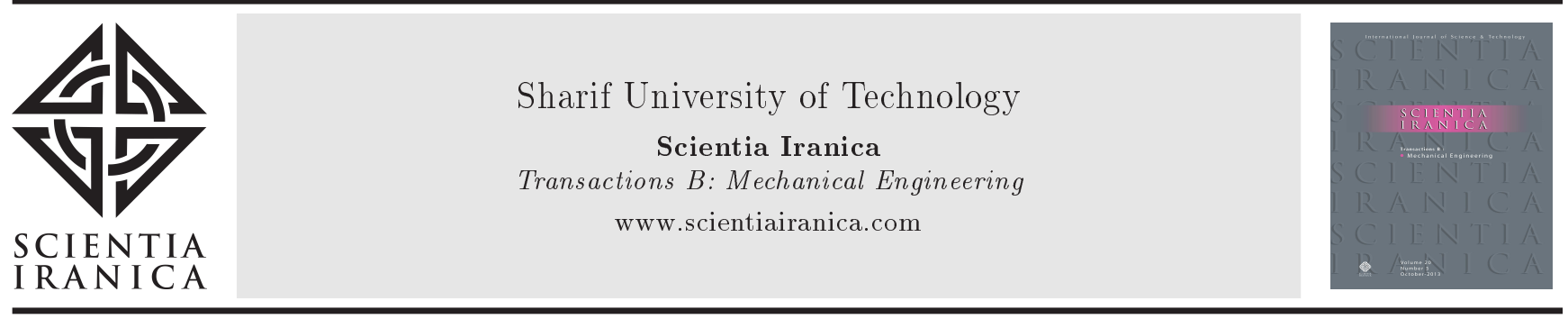

\title{
A modified control strategy for parallel hybrid electric vehicles equipped with continuously variable transmission
}

\author{
M. Delkhosh, M. Saadat Foumani* and F. Falahati \\ School of Mechanical Engineering, Sharif University of Technology, Tehran, P.O. Box 11155-9567, Iran.
}

Received 24 November 2013; received in revised form 20 May 2015; accepted 10 August 2015

\author{
KEYWORDS \\ Hybrid vehicle; \\ Parallel hybrid; \\ Control strategy; \\ Continuously variable \\ transmission; \\ Driving cycle; \\ Fuel consumption.
}

\begin{abstract}
This paper aims to establish a control strategy for parallel hybrid electric vehicles equipped with full-toroidal Continuously Variable Transmission (CVT). First, the advantages of CVT are elucidated. Afterwards, a modified control strategy on the base of Baseline static Control Strategy (BCS) is proposed. Employing this strategy, in some moments, the engine operates in its fuel-optimal point to decrease the vehicle Fuel Consumption (FC). It is demonstrated that the modifications in BCS are applicable using a CVT as the power train. In order to investigate the implemented modification, an optimization on the proposed control strategy and BCS in SC03 driving cycle is accomplished and then, the optimized control strategies are compared. It will be demonstrated that the proposed method is superior to BCS in terms of FC in SC03 driving cycle. Finally, in order to examine generality of the comparison, the optimized control strategies are compared in other driving cycles. It is revealed that the optimized state of the proposed control strategy is advantageous in these cycles.
\end{abstract}

(C) 2016 Sharif University of Technology. All rights reserved.

\section{Introduction}

Subsequent to a decade of research and development in optimization of vehicles, researchers are now seeking new techniques to enhance the vehicles' efficiency and diminish their Fuel Consumption (FC). Employing an electric motor as the power generator of the vehicle, the vehicle emissions are reduced. However, due to insufficient developments of batteries as the power source in these vehicles, researchers have been investigating other methods. One of these methods is to use electric motor and Internal Combustion Engine (ICE) in the vehicle, simultaneously. These vehicles are named Hybrid Electric Vehicles (HEV). One of

*. Corresponding author. Tel.: +98 2166165534 ;

E-mail addresses: m_delkhosh@mech.sharif.edu ( $M$.

Delkhosh); m_saadat@sharif.ir (M. Saadat Foumani);

falahati@mech.sharif.edu (F.Falahati) the HEV's main types is the parallel one (PHEV) in which both motor and ICE are directly connected to wheels and the required power is supplied using both [1]. Due to the direct connection between the ICE and the wheels, it is unlikely to run in fuel-optimal rpm $[2,3]$. The remedy for this deficiency is to use a Continuously Variable Transmission (CVT) as the power train. Instead of 4 or 5 speed ratios, CVT creates continuous speed ratio between the engine and the wheels. Therefore, in case of using CVT, engine revolution is approximately independent of the vehicle speed. Therefore, it is allowed to operate in its fueloptimal rpm. Nowadays, the application of CVT in PHEVs is extensively prevalent [4-7].

One of the main concerns in the design of $\mathrm{HEV}$ is the method of power distribution between its power sources. The proper design of the HEV control strategy leads the engine to operate in its optimal region and results in remarkable improvement in the vehicle FC 
and emission [8]. One of the main strategies that can be used to manage the power distribution is Baseline static Control Strategy (BCS), which is currently employed in different HEVs such as Toyota Prius [9] and Honda Insight [10]. In this strategy, some predefined rules are used to determine the near-optimal power distribution. Also, it attempts to maintain the level of battery energy in the recommended range.

Numerous studies have been implemented on the optimization of the HEV control strategies. Montazeri et al. [11,12] optimized PHEV using genetic algorithm, while the optimization objective was to minimize FC and emissions. Schouten et al. [13] presented fuzzy-logic-based energy management and power control strategy for PHEV and optimized some of its parts. Further, Kheir et al. [14] conducted these studies to minimize emissions. Moreover, Ahn et al. [15] attempted to find the achievable set of optimum operation candidates for the hybrid electric vehicle by optimization of power train. Kang et al. [16] developed a control strategy on the base of the power train losses. In this control strategy, speed ratio of the power train was controlled to operate the power train in the high efficiency region. They found that this control strategy was superior to the control strategy based on the engine operation in its optimal region. Dorri et al. [17] introduced a control strategy on the base of BCS for an HEV equipped with a CVT and optimized it. Wu et al. [18] employed the Particle Swarm Optimization algorithm (PSO) to optimize the parameters of the BCS as well as the size of the HEV components in order to simultaneously minimize FC, emissions, and total production cost. Long and Nhan [19] implemented a similar study utilizing the BEES algorithm.

Some studies have been undertaken on the FC of the vehicles equipped with CVT. Pfiffner et al. [20] introduced a CVT control algorithm to achieve the minimum FC in transient conditions for the case of non-hybrid vehicles. Delkhosh and Foumani [21] simulated a full-toroidal CVT and calculated its efficiency as a function of its geometry and operating condition. They embedded a fixed ratio mechanism between CVT and the final drive and optimized the power train in order to minimize its FC in New European Driving Cycle (NEDC). Lee and Kim [22] studied the fuel economy of PHEV while using CVT and examined the vehicle FC in the Federal Test Procedure (FTP).

The present study attempts to introduce a control strategy for the PHEV outfitted with CVT and optimize it. This strategy is a modified version of BCS. This strategy attempts to use the ICE at the point in which its Brake Specific Fuel Consumption (BSFC) is minimum. To compare this strategy with BCS, first, both control strategies are optimized and then compared. Hence, an optimization on the control parameters of the proposed method and BCS will be conducted, while the objective function is to minimize FC in a driving cycle. Finally, the optimized algorithms will be compared in some of other driving cycles.

\section{Method}

In this section, the model of PHEV is introduced. Hence, the considered power train is introduced and then the proposed control strategy of PHEV is described. Afterwards, the simulation models of its prominent elements are presented. Finally, the method of energy consumption calculation is demonstrated.

\subsection{CVT power train}

As stated above, employing CVT as the PHEV power train can eliminate its main weakness which is ICE operation in the non-optimal area. Despite low efficiency of CVT transmission compared to the conventional one, it has several desirable advantages. A certain advantage of CVT is that it allows the engine to operate at its fuel-optimal rotational speed [23]. The control strategy of CVT's speed ratio is on a base to provide this advantage. In order to determine the control algorithm of CVT's speed ratio and the vehicle $\mathrm{FC}$, the experimental data of the vehicle ICE is necessary. Figure 1 shows the BSFC contours of the considered vehicle's ICE. This data is presented by the ICE manufacturer.

As displayed in Figure 1, for any value of the ICE power, there is a specific rotational speed in which BSFC is minimal. These points are on the "Optimum Curve". There is a point on this curve that has minimal BSFC, called "BSFC-optimal point". At this point, ICE revolution $\left(\omega_{\text {opt }}\right)$, power $\left(P_{\text {opt }}\right)$, and $\mathrm{BSFC}\left(\mathrm{BSFC}_{\mathrm{opt}}\right)$ are $3000 \mathrm{rpm}, 36 \mathrm{~kW}$, and

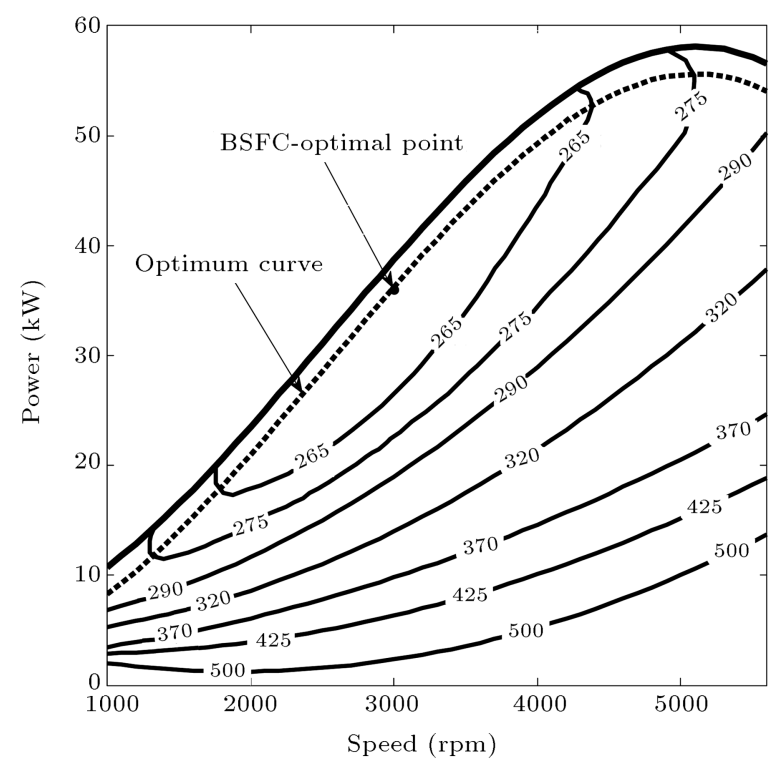

Figure 1. The Brake Specific Fuel Consumption (BSFC) contours of the vehicle's engine. 
Table 1. The considered vehicle and engine characteristics.

\begin{tabular}{cccc}
\hline Parameter & Value & Parameter & Value \\
\hline$f_{r}$ & 0.013 & $m$ & $1510 \mathrm{~kg}$ \\
$C_{D}$ & 0.355 & $R_{d}$ & $0.279 \mathrm{~m}$ \\
$A$ & $2.09 \mathrm{~m}^{2}$ & $\eta_{d}$ & $90 \%$ \\
$n_{d}$ & 3.895 & $\rho_{\text {fuel }}$ & $720 \mathrm{~kg} / \mathrm{m}^{3}$ \\
$P_{E \max }$ & $58 \mathrm{~kW}$ at $5500 \mathrm{rpm}$ & $T_{E \max }$ & $126 \mathrm{Nm}$ at $3600 \mathrm{rpm}$ \\
\hline
\end{tabular}

$256.8 \mathrm{~g} / \mathrm{kWh}$, respectively. In the control strategy of CVT as the power train of the non-hybrid vehicles, by considering the required power of the engine, $\omega_{\text {opt }}$ can be determined and with regard to the vehicle speed, speed ratio of CVT is obtainable.

The method of FC calculation for the vehicle equipped with CVT is explained in [21]. The considered vehicle and engine characteristics, which are necessary to calculate FC, are shown in Table 1.

\subsection{Control strategy of $\mathrm{PHEV}$}

The strategy of power distribution between PHEV power sources has a major role in energy consumption of these vehicles. In this section, it is attempted to establish a control strategy for PHEV equipped with CVT. The architecture of the considered PHEV is displayed in Figure 2. This vehicle is composed of fuel tank, ICE, power trains (Gearbox (GB) and CVT), Battery (Batt), electric Motor/Generator (MG), Torque Coupler (TC), and clutch (CL). In addition, PHEV includes a control unit which determines the manner of elements in different driving conditions.

The proposed control strategy needs some inputs and outputs. According to Figure 2, the inputs of the proposed control unit are the state of charge of the battery (battery energy normalized with respect to its maximum energy, SOC), velocity, acceleration and the required power of the vehicle, and CVT efficiency achieved from its model. The control unit has some precalculated parameters which are the engine BSFC data, the efficiency map of MG, and some scalar parameters that will be introduced in the following. The control unit determines which part of the demanded power must be provided by each ICE and MG. Also, it determines the rotational speed of the ICE, the battery mode (charge/discharge), and the CVT speed ratio.

The proposed control strategy is a modified version of BCS method. In the BCS method, the engine is the primary source of power and the electric motor is the secondary power generator. It attempts to reduce the vehicle FC regardless of its emissions [19]. This method is thoroughly explained in $[11,24]$. Similar to the BCS, the proposed strategy includes some predefined rules used to manage the power distribution in the HEV. These rules are described as follows:

1. If the battery SOC is more than its highest desired value $\left(H_{\mathrm{SOC}}\right)$, then the battery and electric motor will supply this power, and the engine will be turned off;

2. If the vehicle speed is lower than the speed limit $\left(V_{L}\right)$, or the required power $\left(P_{\text {req }}\right)$ is lower than

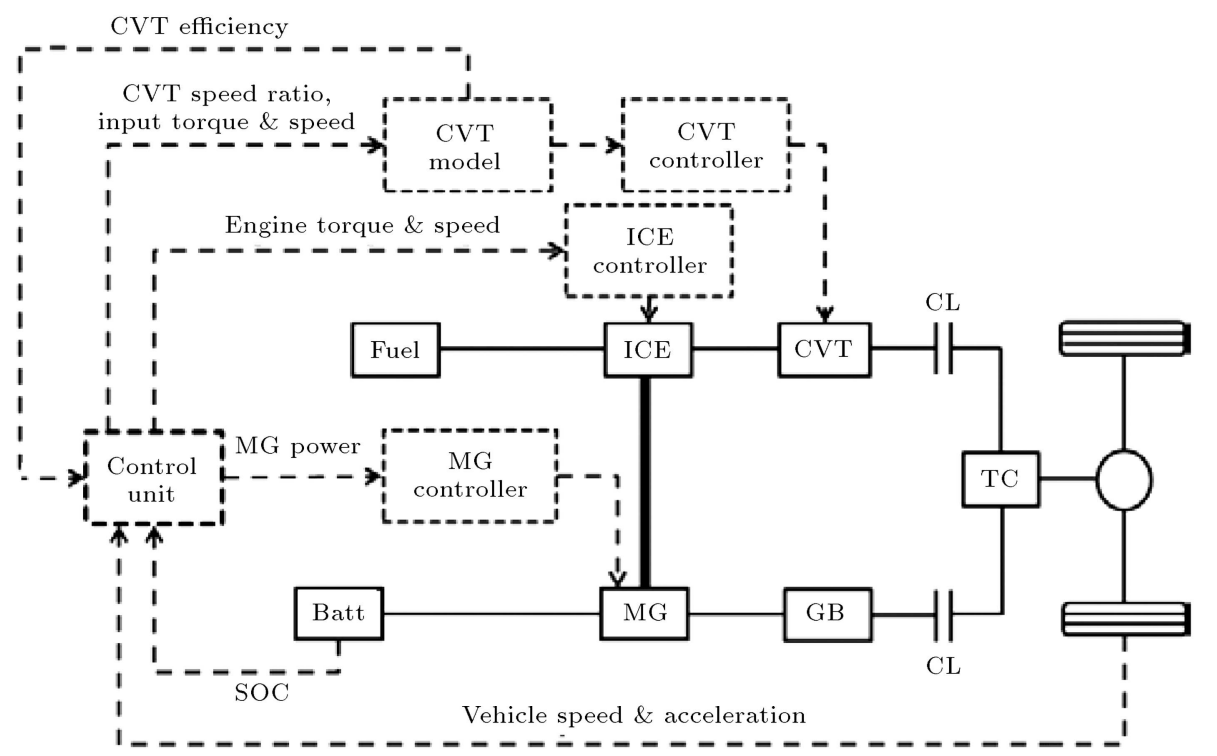

Figure 2. The architecture of PHEV and diagram of the control unit's input and output. 
a percent $\left(t_{\text {off }}\right)$ of the engine maximum power $\left(P_{E \max }\right)$, and SOC is more than the lowest desired $\operatorname{SOC}\left(L_{\mathrm{SOC}}\right)$, then the battery and electric motor will provide the requested power and the engine will be turned off;

3. If $P_{\text {req }}$ is lower than a percent $\left(t_{\min }\right)$ of $P_{E \max }$ and $\mathrm{SOC}<L_{\mathrm{SOC}}$, then $P_{E}=t_{\mathrm{min}} P_{E \max }$, and the additional power will be used to charge the battery by means of MG;

4. If $P_{\text {req }}$ is more than $t_{\text {min }} P_{E \text { max }}$ or $t_{\text {off }} P_{E \max }$ and SOC $<H_{\mathrm{SOC}}$, the ICE will operate in "BSFCoptimal point", and the supplementary power will be used to charge the battery. In cases that $P_{\text {req }}$ is more than $P_{\mathrm{opt}}$ and $\mathrm{SOC}>L_{\mathrm{SOC}}$, the engine will operate in BSFC-optimal point and the battery and MG must provide the rest of $P_{\text {req }}$. In these cases, if the MG limits the value of power flow through the battery, it will be disengaged. Otherwise, the ICE will not necessarily operate in its BSFC-optimal point;

5. In the braking mode, the battery will be charged by regenerative brake until $\mathrm{SOC}=H_{\mathrm{SOC}}$;

6. When the vehicle is at standstill, the ICE and MG are turned off.

In all rules (except the 4th rule), the transferred power is constrained by the MG maximum power. During the battery charging, if the transmitted power to the battery is more than the maximum power of the generator $\left(P_{G \text { max }}\right)$, it will be equal to $P_{G \max }$, and the engine must provide sum of $P_{G \text { max }}$ and $P_{\text {req }}\left(P_{E}=P_{G \text { max }}+\right.$ $\left.P_{\text {req }}\right)$. Similarly, in discharge mode, the $\mathrm{MG}$ and engine supply the needed power $\left(P_{E}=P_{\text {req }}-P_{M \text { max }}\right)$, where $P_{M \text { max }}$ is maximum power of the motor. In these cases, the engine operates on the optimum curve (see Figure 1) and the engine rpm will be achieved for the specified value of the engine power. Knowing the value of the engine revolution and the vehicle speed, the speed ratio of the power train can be obtained.

As mentioned earlier, the proposed control strat-

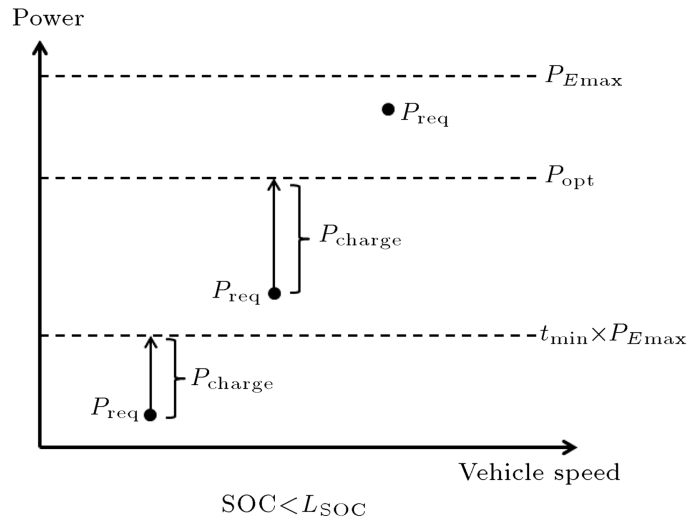

egy is a modified version of BCS. In the presented method, the fourth rule is different from BCS rules. According to this rule, the strategy attempts to use the ICE in its BSFC-optimal point (see Figure 1) to decrease the vehicle $\mathrm{FC}$ in the driving cycle. Operating in the BSFC-optimal point may increase its FC (which is directly related to $P_{E} \times \mathrm{BSFC}$ ). However, since the ICE operates in its efficient point and the extra power can be used to charge the battery, the overall FC (considering the energy saved in the battery) over the driving cycle may decrease.

The second advantage of the proposed strategy is its lower parameters compared to the BCS. In the BCS, if the $P_{\text {req }}$ is more than $t_{\text {min }} P_{E \text { max }}$ or $t_{\text {off }} P_{E \text { max }}$ and $\mathrm{SOC}<H_{\mathrm{SOC}}$, the operating point of the ICE is determined using some additional parameters which need to be optimized to reach an optimum strategy. In the proposed strategy, these parameters have been eliminated and the ICE is set to operate in a specific point which simplifies the control strategy.

The schematic of control strategy is illustrated in Figure 3. In this figure, the second, third, and fourth rules of the proposed method are presented. The other rules are clear and do not need to be displayed in the figure.

In the application of conventional transmissions, engine revolution is proportional to the vehicle speed and for a specific value of vehicle speed, engine rpm is definite according to the transmission speed ratio. This rpm is not necessarily the same $\omega_{\text {opt }}$ (BSFCoptimal point (see Figure 1)). Increasing the number of speed ratios in the conventional transmission leads to an escalation in the achievable values of en gine rpm for a specific value of the vehicle speed and the possibility of operating on the BSFC-optimal point increases. If the transmission has infinite number of speed ratios, $\omega_{\text {opt }}$ will be attainable for any value of vehicle speed. CVT gives this advantage. Therefore, as demonstrated in Figure 3, in any time of driving cycle and for any value of the vehicle speed, engine revolution can differ and move toward the BSFC-optimal point. Thus, the

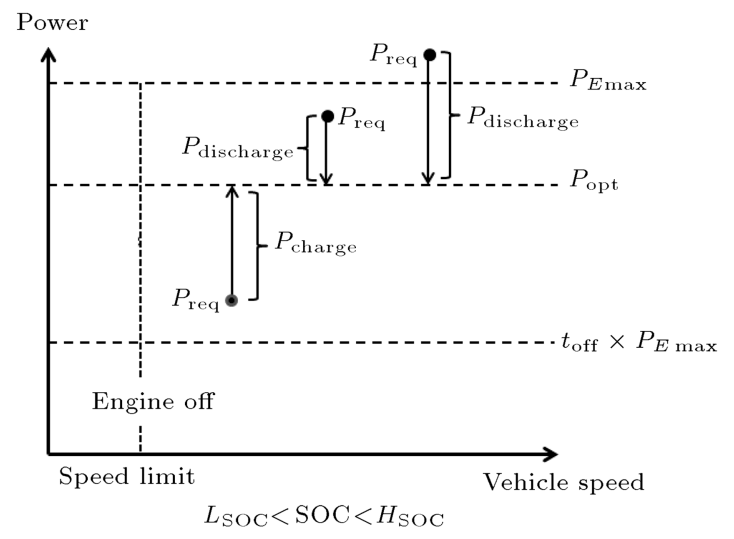

Figure 3. The schematic of control strategy. 
fourth rule of the proposed strategy is possible only through application of CVT.

\subsection{Models of PHEV main components}

In this section, models of PHEV elements, except the engine described in the preceding section, are presented.

The considered CVT for PHEV is a full-toroidal CVT. It has been comprehensively introduced and simulated in $[25,26]$ and its efficiency has been calculated. As demonstrated in [25], the efficiency of fulltoroidal CVT is a function of its speed ratio, input torque, rotational speed of the disks, and also the oil operating conditions (i.e., temperature and pressure). These inputs are determined in each moment of driving cycle according to the engine torque and revolution. The relations required to calculate the efficiency of this transmission are presented as follows:

$$
\begin{aligned}
& \text { SpinLoss }=\left(M_{S_{\text {in }}} \omega_{S p_{\text {in }}}+M_{S_{\text {out }}} \omega_{S p_{\text {out }}}\right) n, \\
& \text { SlipLoss }=\left(\mu_{\text {in }} S p_{\text {in }} r_{\text {in }} \omega_{\mathrm{CVT}_{\text {in }}}\right. \\
&\left.+\mu_{\text {out }} S p_{\text {out }} r_{\text {out }} \omega_{\mathrm{CVT}_{\text {out }}}\right) n F_{N}, \\
& \eta_{\text {CVT }}=\frac{\text { Input Power-SpinLoss-SlipLoss }}{\text { Input Power }} .
\end{aligned}
$$

The values of the normal force, spin moments, $r_{\text {in }}$ and $r_{\text {out }}$, and also rotational speeds $\left(\omega_{\mathrm{CVT}_{\text {in }}}, \omega_{\mathrm{CVT}_{\text {out }}}\right.$, $\left.\omega_{S p_{\text {in }}}, \omega_{S p_{\text {out }}}\right)$ are determined regarding the CVT input torque and speed and also its speed ratio (which determines the orientation of the roller). On the other hand, the values of the traction coefficients depend on the viscosity of oil which is a function of the oil pressure and temperature [21].

Electric motor is another key element of the HEVs. The selected electric motor with the assistance of the engine should satisfy "Partnership for a New Generation of Vehicles (PNGV)" criteria in order to ensure that the vehicle hybridization does not sacrifice the vehicle dynamic performances. These criteria are illustrated in Table 2 [27]. It is demonstrated that the vehicle satisfies PNGV criteria.

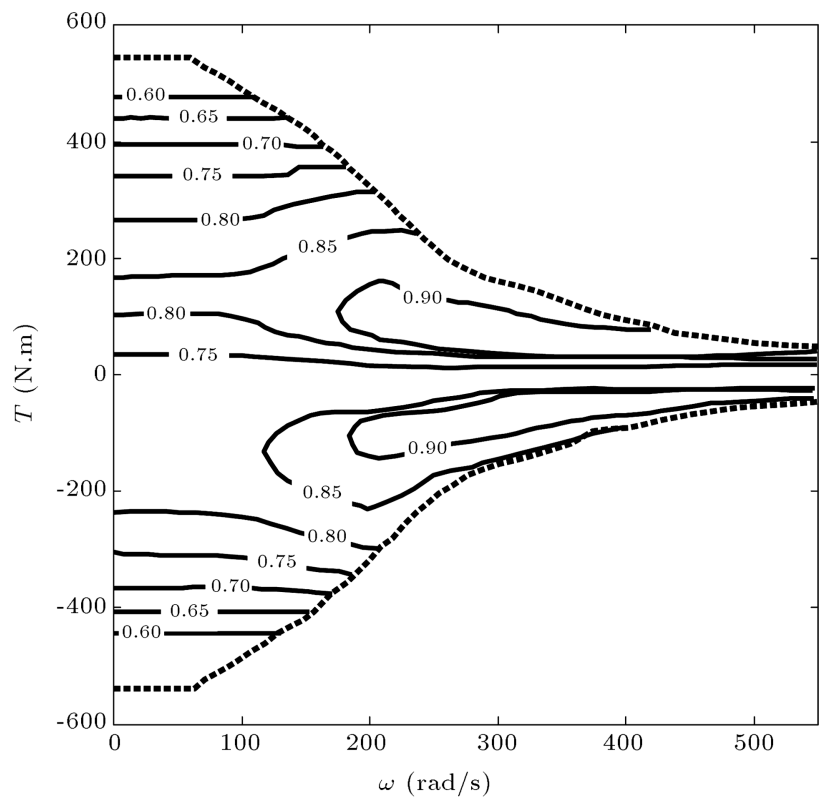

Figure 4. The variations of efficiency and torque of the motor/generator with respect to its $\mathrm{rpm}$ [28].

The selected MG for meeting these criteria is an asynchronous induction motor. Its maximum power is $23 \mathrm{~kW}$. Figure 4 shows the variations of torque and efficiency contours of the MG against its revolution [28]. The selected motor is used as a generator through braking, which charges the battery. In our model, braking energy is recovered from the front wheels. Hence, in order to prevent instability of the vehicle, $60 \%$ of braking energy is regained, and the rest of the required braking energy is provided by frictionbased brakes $\left(\eta_{r b}=0.6\right)$ [17]. It is notable that the percentage of braking force, which should be provided by the front brake, depends on the deceleration value [29]. However, as mentioned, the percentage considered in this paper is a rough estimate. It is because that considering the front brake force as a function of the deceleration value is not the aim of this paper. Moreover, since the proposed strategy and BCS have similar rules for the braking mode, this simplification does not impact the result of the comparison

Table 2. PNGV criteria for passenger cars and the achieved values by the vehicle.

\begin{tabular}{lll}
\hline & \multicolumn{1}{c}{ PNGV criteria } & \multicolumn{1}{c}{ Achieved value } \\
\hline Gradeability & $\geq 88.5 \mathrm{~km} / \mathrm{h}$ at $6.5 \%$ grade for $20 \mathrm{~min}$ & $88.5 \mathrm{~km} / \mathrm{h}$ at $20 \%$ grade for $20 \mathrm{~min}$ \\
& $0-97 \mathrm{~km} / \mathrm{h}: \leq 12 \mathrm{sec}$ & $8.3 \mathrm{sec}$ \\
Acceleration time for & $0-137 \mathrm{~km} / \mathrm{h}: \leq 23.4 \mathrm{sec}$ & $18.8 \mathrm{sec}$ \\
& $64-97 \mathrm{~km} / \mathrm{h}: \leq 5.3 \mathrm{sec}$ & $4.9 \mathrm{sec}$ \\
& $\geq 137 \mathrm{~km} / \mathrm{h}$ & $189 \mathrm{~km} / \mathrm{h}$ \\
Maximum speed & $\geq 0.5 \mathrm{~g}$ & $0.6 \mathrm{~g}$ \\
Maximum acceleration & $\geq 42.7 \mathrm{~m}$ & $72 \mathrm{~m}$ \\
\hline
\end{tabular}


Table 3. The efficiency of other parts of PHEV [30].

\begin{tabular}{cc}
\hline PHEV element & Value \\
\hline$\eta_{r b}$ & 0.6 \\
$\eta_{\mathrm{GB}}$ & 0.9 \\
$\eta_{\mathrm{TC}}$ & 0.95 \\
\hline
\end{tabular}

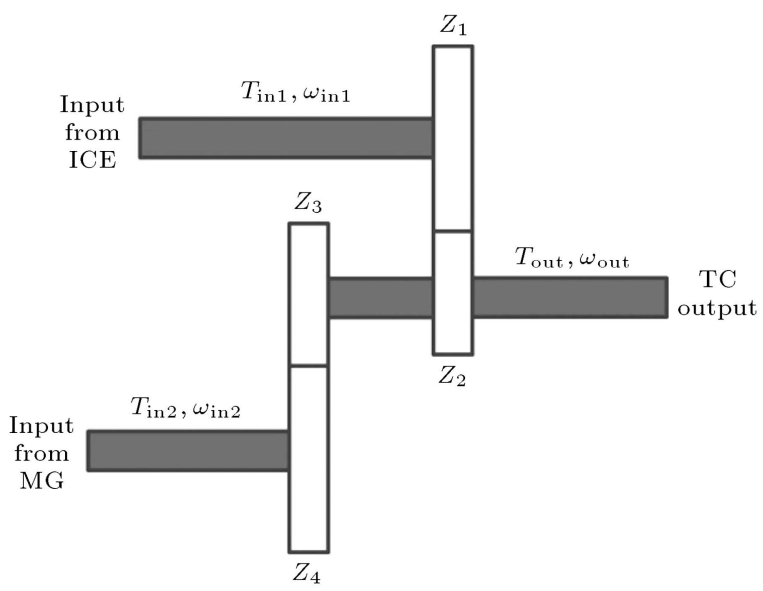

Figure 5. Structure of the employed torque coupler.

implemented between the proposed strategy and the BCS.

The efficiency of other parts of PHEV is presented in Table 3. Based on small variations in the efficiency of mated gears due to variation of their speeds and input torques, we assume that their efficiency is fixed [30].

The torque coupler employed in this study is a conventional TC. This component collects the torques of the ICE and MG and delivers them to the final drive to propel the vehicle. In addition, while the provided torque by the ICE is more than the required value, the additional torque is transmitted through $\mathrm{TC}$ to the $\mathrm{MG}$ in order to charge the battery. Also, during the braking, the TC transmits the braking torque to the MG to charge the battery. The structure of this component is shown in Figure 5. The relations among the TC elements are presented below:

$$
\begin{aligned}
& \omega_{\mathrm{in} 1}=\frac{Z_{2}}{Z_{1}} \omega_{\mathrm{TCout}}, \quad \omega_{\mathrm{in} 2}=\frac{Z_{3}}{Z_{4}} \omega_{\mathrm{TCout}}, \\
& T_{\mathrm{out}}=T_{\mathrm{in} 1} \frac{Z_{2}}{Z_{1}} \eta_{\mathrm{TC}}+T_{\mathrm{in} 2} \frac{Z_{3}}{Z_{4}} \eta_{\mathrm{TC}}^{\alpha} .
\end{aligned}
$$

In Eq. (5), $\alpha$ means the power flow direction of the MG. If the battery is in the charge mode (negative MG torque), $\alpha=-1$; and if it is in discharging mode, $\alpha=1$ (positive MG torque).

The selected battery is a Lithium-Ion Polymer rechargeable battery. Its capacity, nominal voltage, internal impedance, and number of modules are $10.05 \mathrm{Ah}, 14.8 \mathrm{~V}, 15 \mathrm{~m} \Omega$, and 20 , respectively. Its maximum allowable currents in the charge and discharge modes are 10.05A and 120A, respectively. Since internal impedance of the selected battery slightly varies with SOC, its losses are approximately fixed. The average efficiency of the battery is 0.98 considering its voltage and current curves during charge and discharge.

\subsection{Energy consumption versus fuel consumption}

In the HEVs, energy flows to wheels through engine and electric motor. Therefore, energy is consumed by both of these power sources. The equivalent FC of the PHEV can be calculated [31]. However, for a long run, the difference between the final and initial SOCs $(\Delta$ SOC $)$ has a negligible effect on the total energy consumption compared to the vehicle FC. Therefore, the vehicle $\mathrm{FC}$ is considered as the criterion for comparing the mentioned control strategies. In order to decrease the effect of $\triangle \mathrm{SOC}$ on the vehicle energy consumption, the vehicle is considered in some numbers of the considered drive cycle until the value of $\mathrm{FC}$ converges. In this state, $\triangle$ SOC must be divided by the number of cycles to find its average in each cycle. If a large number of cycles are considered, the average of $\triangle \mathrm{SOC}$ in each cycle will be a low value. If the $\mathrm{FC}$ converges during these cycles, SOC variation will have smaller impact on the vehicle energy consumption. It is revealed that $\mathrm{FC}$ of the vehicle converges in 10 cycles. Therefore, it is calculated during 15 cycles to ensure the accuracy of energy consumption. It is worth mentioning that the employed approach is one of the methods employed to eliminate the effect of electric energy consumption on the overall energy consumption [32].

\section{Optimization}

To make a precise comparison between the proposed method and BCS and determine the optimum values of the control parameters, an optimization is implemented on them. Afterwards, the optimized control strategies will be compared.

In the present study, PSO is used to optimize the control strategies. This method is used widely in various fields because of its high rate of convergence [33]. In this method, initial values of optimization parameters are selected randomly. Each set of solutions is considered as a particle which has specific velocity and position. At each iteration of the optimization process, according to Eqs. (6) and (7), its velocity and position are updated considering its best previous experience and the best experience of other particles [34]:

$$
\begin{aligned}
V_{i, t+1}= & k\left[\omega V_{i, t}+c_{1} r_{1, t}\left(P_{i, t}-X_{i, t}\right)\right. \\
& \left.+c_{2} r_{2, t}\left(P_{g, t}-X_{i, t}\right)\right] \\
X_{i, t+1}= & X_{i, t}+V_{i, t+1}
\end{aligned}
$$


Table 4. The optimization parameters and their range.

\begin{tabular}{cc}
\hline $\begin{array}{c}\text { Optimization } \\
\text { parameter }\end{array}$ & Range \\
\hline$L_{\mathrm{SOC}}$ & {$[0.2-0.55]$} \\
$H_{\mathrm{SOC}}$ & {$[0.55-0.8]$} \\
$t_{\mathrm{off}}$ & {$[0.01-0.6]$} \\
$t_{\mathrm{min}}$ & {$[0.01-0.6]$} \\
$V_{L}(\mathrm{~m} / \mathrm{s})$ & {$[2-12]$} \\
\hline
\end{tabular}

The process of updating the velocity and position of each particle continues until the best value of objective function is gained through convergence and the best solution is found.

In the present study, the vehicle motion is considered in SC03 driving cycle. The reason behind considering this cycle is that the vehicle experiences high accelerations and, there is a need for high power. Consequently, the vehicle hybridization exerts remarkable effects in this cycle.

As discussed, the objective function of the optimization is the vehicle FC calculated at the end of 15 cycles of SC03. The optimization parameters are the same as those of control strategy. These parameters and their ranges are presented in Table 4. As stated by the battery manufacturer, its reasonable SOC range is $[0.2-0.8]$. The allowable ranges of $L_{\mathrm{SOC}}$ and $H_{\mathrm{SOC}}$ are determined regarding this fact. follows:

The optimization problem can be formulated as

\section{Minimize FC}

where $X=\left[L_{\mathrm{SOC}}, H_{\mathrm{SOC}}, t_{\mathrm{off}}, t_{\mathrm{min}}, V_{L}\right]^{T}$.

The optimization program was run for several times with random initial values of optimization parameters. It is demonstrated that for different initial values of optimization parameters, the optimum FC is the same. Figure 6 shows the variations of objective function through several times of optimization runs for both of the presented methods.

According Figure 6, the objective function is obtained through convergence during 10 iterations. In addition, it is revealed that initial values of optimization parameters do not impact on the optimum objective function.

Table 5 presents the optimum values of the optimization parameters and objective function for control patterns.

With respect to Figure 6 and Table 5, the optimized form of the proposed method is superior to the optimized BCS in terms of FC. Through application of the proposed method, FC is about $16 \%$ lower compared to the application of BCS method. Thus, modifying BCS according to the mentioned rules in Section 2.2 is beneficial.

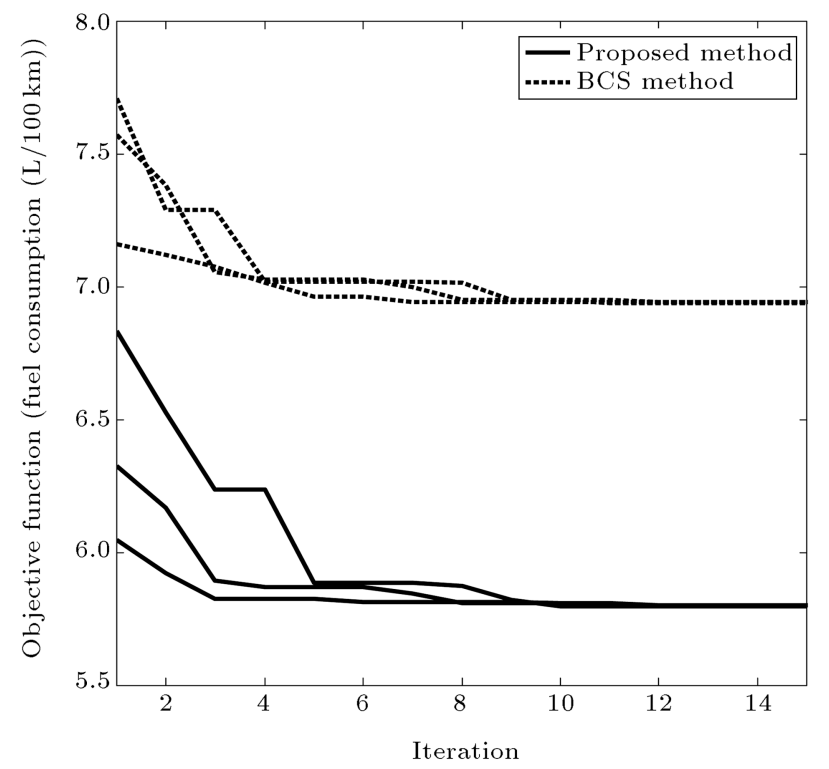

Figure 6. The variations of objective function for both of the mentioned methods during optimization process.

Table 5. The optimum value of the optimization parameters and objective function for control patterns.

\begin{tabular}{ccc}
\hline & $\begin{array}{c}\text { Proposed } \\
\text { method }\end{array}$ & $\begin{array}{c}\text { BCS } \\
\text { method }\end{array}$ \\
\hline $\boldsymbol{L}_{\text {SOC }}$ & 0.47 & 0.4 \\
$\boldsymbol{H}_{\text {S OC }}$ & 0.66 & 0.69 \\
$\boldsymbol{t}_{\text {off }}$ & 0.3 & 0.12 \\
$\boldsymbol{t}_{\text {min }}$ & 0.3 & 0.05 \\
$\boldsymbol{V}_{\boldsymbol{L}}(\mathbf{m} / \mathbf{s})$ & 5.5 & 10.7 \\
$\mathbf{F C ~}(\mathbf{L} / \mathbf{1 0 0} \mathbf{~ k m})$ & 5.81 & 6.92 \\
\hline
\end{tabular}

Table 6. FC comparison between optimized methods in different driving cycles.

\begin{tabular}{cccc}
\hline & $\begin{array}{c}\text { BCS } \\
\text { method }\end{array}$ & $\begin{array}{c}\text { Proposed } \\
\text { method }\end{array}$ & $\begin{array}{c}\text { Difference } \\
\text { percent }\end{array}$ \\
\hline FTP & 6.55 & 5.55 & $15 \%$ \\
US06 & 7.2 & 6 & $17 \%$ \\
$\begin{array}{c}\text { Urban } \\
\text { dynamometer }\end{array}$ & 6.6 & 5.5 & $17 \%$ \\
\hline
\end{tabular}

Figure 7 shows the variation of $\mathrm{FC}$ for both of the control strategies with respect to the number of drive cycle. As can be seen, after 10 cycles, FC converges.

The optimized methods are compared in the other driving cycles to ascertain if the proposed method is better than BCS in the other driving patterns.

Table 6 shows the values of FC in FTP, US06, and Urban Dynamometer drive cycles for the application of the optimized BCS and the proposed method.

According to Table 6 , in all of the considered drive cycles, the optimized form of the proposed method is 


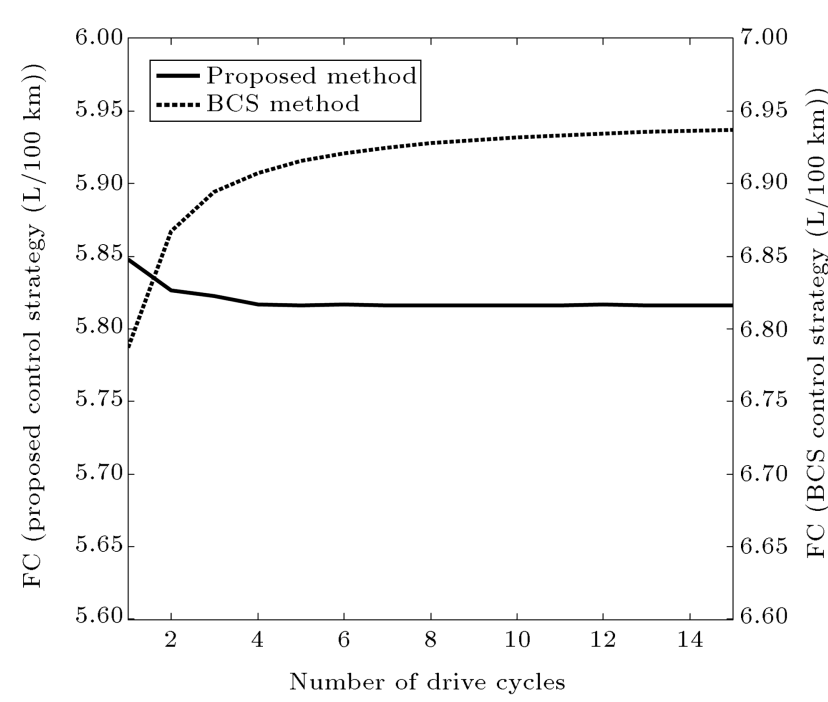

Figure 7. The variations of $\mathrm{FC}$ during driving cycles for both of the considered control strategies.

superior to the optimized BCS in terms of FC. Therefore, it seems that the achieved optimized parameters as well as the optimized objective for the proposed method are not highly sensitive to the type of drive cycle.

\section{Conclusion}

In this paper, a strategy was established based on BCS to control the power transfer in PHEV. The selected vehicle was employing a full-toroidal CVT as the power train and its efficiency was considered in the control strategy using the model presented in [25]. A modified version of BCS was introduced. This strategy attempted to use the ICE in its BSFC-optimal point to decrease the overall FC in driving cycle and also simplify the BCS. It was demonstrated that the added rule was applicable in case of using a CVT as the vehicle power train. The control parameters of the proposed control strategy and BCS were optimized using PSO, while the objective was to minimize the vehicle $\mathrm{FC}$ in $\mathrm{SC0} 3$ driving cycle. It was found that the vehicle $\mathrm{FC}$ for the application of the optimized form of the proposed control strategy was $16 \%$ lower than its value for the application of the optimized BCS and, therefore, modification of BCS in accordance with the mentioned strategy was beneficial. Moreover, the optimized control strategies were compared in the other drive cycles and it was revealed that the proposed method resulted in low FC compared to the case of BCS method.

This study suffers from a number of limitations such as:

1. The response time of CVT speed ratio variation was not considered;

2. The vehicle emission was not regarded.

\section{Nomenclature}

A

Frontal area of the vehicle

$\mathrm{BSFC}_{\text {opt }}$ Engine optimum BSFC

$c_{1}, c_{2} \quad$ Constant values in PSO

$C_{D} \quad$ Aerodynamic drag coefficient

$F_{N} \quad$ Normal force at the contact point

$f_{r} \quad$ Rolling resistance coefficient of the vehicle

$H_{\mathrm{SOC}} \quad$ The highest desired value of battery SOC

$k$

$m$

$M_{S_{\text {in }}}$

$M_{S_{\text {out }}}$

$n$

$n_{d}$

$P_{E}$

$P_{E \max }$

Constriction coefficient

Vehicle mass

Spin moment on the input disk

Spin moment on the output disk

Number of the rollers

Speed ratio of the final drive

Engine power

$P_{g, t} \quad$ The best global experience

$P_{G \text { max }} \quad$ Maximum power of the generator

$P_{i, t} \quad$ The best personal experience of the particle

$P_{\text {opt }} \quad$ Engine optimum power

$P_{\text {req }} \quad$ Required power

$r_{1, t}, r_{2, t} \quad$ Random numbers in PSO

$R_{d} \quad$ Wheel's radius

$r_{\text {in }} \quad$ The distance between the rotation axis of input disk and the contact point

$r_{\text {out }} \quad$ The distance between the rotation axis of output disk and the contact point

SlipLoss Power losses of CVT caused by slip motion

SpinLoss Power losses of CVT caused by spin motion

$S p_{\text {in }} \quad$ Slip coefficient in the input disk

$S p_{\text {out }} \quad$ Slip coefficient in the output disk

$T_{E \max } \quad$ Maximum torque of engine

$T_{\text {in1 }} \quad$ TC input torque from ICE

$T_{\text {in2 }} \quad$ TC input torque from $\mathrm{MG}$

$t_{\text {min }} \quad$ Minimum power threshold when $\mathrm{SOC}<\mathrm{L}_{\mathrm{SOC}}$

$t_{\text {off }} \quad$ Minimum power threshold when $\mathrm{SOC}>\mathrm{L}_{\mathrm{SOC}}$

$T_{\text {out }} \quad$ TC output torque

$V_{i, t} \quad$ Particle velocity

$V_{L} \quad$ Vehicle speed limit

$X_{i, t} \quad$ Particle position at moment $t$

$X_{i, t+1} \quad$ Particle position at moment $t+1$ 


$\begin{array}{ll}Z & \text { The teeth number of the gears in TC } \\ \omega & \text { Momentum factor in PSO } \\ \omega_{\mathrm{CVT}_{\mathrm{in}}} & \text { Rotational speed of CVT input disk } \\ \omega_{\mathrm{CVT}_{\text {out }}} & \text { Rotational speed of CVT output disk } \\ \omega_{\mathrm{in} 1} & \text { Rotational speed of the TC shaft } \\ & \text { connected to ICE } \\ \omega_{\text {in } 2} & \text { Rotational speed of the TC shaft } \\ \omega_{\text {opt }} & \text { connected to MG } \\ \omega_{\text {out }} & \text { Engine optimum rpm } \\ \omega_{S p_{\text {in }}} & \text { Rotational speed of the TC output } \\ \omega_{S p_{\text {out }}} & \text { Spin speed of input disk } \\ \eta_{d} & \text { Efficiency of final drive } \\ \eta_{\mathrm{GB}} & \text { Efficiency of GB } \\ \eta_{r b} & \text { Regenerative braking efficiency } \\ \eta_{\mathrm{TC}} & \text { Efficiency of torque coupler } \\ \rho_{\mathrm{fuel}} & \text { Density of fuel }\end{array}$

\section{References}

1. Hutchinson, T., Burgess, S. and Herrmann, G. "Current hybrid-electric powertrain architectures: Applying empirical design data to life cycle assessment and whole-life cost analysis", Int. J. of Appl. Energ., 119, pp. 314-329 (2014).

2. Shaw, D., Cai, J.Y. and Liu, C.T. "Efficiency analysis and controller design of a continuous variable planetary transmission for a CAES wind energy system", Int. J. of Appl. Energ., 100, pp. 118-126 (2012).

3. Delkhosh, M. and Saadat Foumani, M. "Introduction and optimization of a power split continuously variable transmission including several fixed ratio mechanisms", Sci. Iran, 22(1), pp. 226-234 (2015).

4. Ryu, W., Cho, N., Yoo, I., Song, H. and Kim, H. "Performance analysis of a CVT clutch system for a hybrid electric vehicle", Int. J. of Automot Techn., 10(1), pp. 115-121 (2009).

5. Wang, C.L., Yin, C.L., Zhang, T. and Zhu, L. "Powertrain design and experiment research of a parallel hybrid electric vehicle", Int. J. of Automot Techn., 10(5), pp. 589-596 (2009).

6. Mansour, C. and Clodic, D. "Optimized energy management control for the toyota hybrid system using dynamic programming on a predicted route with short computation time", Int. J. of Automot Techn., 13(2), pp. 309-324 (2012).

7. Suh, B., Chang, Y.H., Han, S.B. and Chung Y.J. "Simulation of a powertrain system for the diesel hybrid electric bus", Int. J. of Automot Techn., 13(5), pp. 701-711 (2012).

8. Enang, W., Bannister, C., Brace, C. and Vagg, C. "Modelling and heuristic control of a parallel hybrid electric vehicle", P I Mech. Eng. D-J Aut., pp. 1-20 (2015).
9. Banvait. H., Anwar, S. and Chen, Y. "A rule-based energy management strategy for Plug-in Hybrid Electric Vehicle (PHEV)", in American Control Conference (ACC), pp. 3938-3943 (2009).

10. Safaei, A., Ha'iri-Yazdi, M.R., Esfahanian, V., Esfahanian, M., Tehrani, M.M. and Nehzati, H. "Designing an intelligent control strategy for hybrid powertrains utilizing a fuzzy driving cycle identification agent", $P$ I Mech. Eng. D-J Aut., pp. 1-20 (2014).

11. Montazeri-Gh, M., Poursamad, A. and Ghalichi, B. "Application of genetic algorithm for optimization of control strategy in parallel hybrid electric vehicles", $J$. of Franklin Inst., 343(4), pp. 420-435 (2006).

12. Montazeri-Gh, M. and Poursamad, A. "Application of genetic algorithm for simultaneous optimisation of HEV component sizing and control strategy", Int. J. Altern. Propul., 1(1), pp. 63-78 (2006).

13. Schouten, N.J., Salman, M.A. and Kheir, N.A. "Energy management strategies for parallel hybrid vehicles using fuzzy logic", J. of Control Eng. Prac., 11(2), pp. 171-177 (2003).

14. Kheir, N.A., Salman, M.A. and Schouten, N.J. "Emissions and fuel economy trade-off for hybrid vehicles using fuzzy logic", J. of Math. Comput. Simulat., 66(2), pp. 155-172 (2004).

15. Ahn, K., Cho, S. and Cha, S.W. "Optimal operation of the power-split hybrid electric vehicle powertrain", P I Mech. Eng. D-J Aut., 222(5), pp. 789-800 (2008).

16. Kang, J., Choi, W. and Kim, H. "Development of a control strategy based on the transmission efficiency with mechanical loss for a dual mode power split-type hybrid electric vehicle", Int. J. of Automot Techn., 13(5), pp. 825-833 (2012).

17. Dorri, M. and Shamekhi, A.H. "Design and optimization of a new control strategy in a parallel hybrid electric vehicle in order to improve fuel economy", $P$ I Mech. Eng. D-J Aut., 225(6), pp. 747-759 (2011).

18. Wu, J., Zhang, C.H., and Cui, N.X. "PSO algorithmbased parameter optimization for HEV powertrain and its control strategy", Int. J. of Automot. Techn., 9(1), pp. 53-59 (2008).

19. Long, V.T. and Nhan, N.V. "Bees-algorithm-based optimization of component size and control strategy parameters for parallel hybrid electric vehicles", Int. J. of Automot Techn., 13(7), pp. 1177-1183 (2012).

20. Pfiffner, R., Guzzella, L. and Onder, C.H. "Fueloptimal control of CVT powertrains", J. of Control Eng. Prac., 11(3), pp. 329-336 (2003).

21. Delkhosh, M. and Foumani, M.S. "Optimisation of fulltoroidal continuously variable transmission in conjunction with fixed ratio mechanism using particle swarm optimisation", Vehicle Syst. Dyn., 51(5), pp. 671-683 (2013).

22. Lee, H. and Kim, H. "Improvement in fuel economy for a parallel hybrid electric vehicle by continuously variable transmission ratio control", P I Mech. Eng. D-J Aut., 219(1), pp. 43-51 (2005). 
23. Delkhosh, M., Saadat Foumani, M. and Boroushaki, M. "Geometrical optimization of parallel infinitely variable transmission to decrease vehicle fuel consumption", Mech. Based Des Struc., 24(4), pp. 483-501 (2014).

24. Johnson, V.H., Wipke, K.B. and Rausen, D.J. "HEV control strategy for real-time optimization of fuel economy and emissions", SAE Trans., 109(3), pp. 1677-1690 (2000).

25. Delkhosh, M. and Saadat Foumani, M. "Multiobjective geometrical optimization of full toroidal CVT", Int. J. of Automot Techn., 14(5), pp. 707-715 (2013).

26. Carbone, G., Mangialardi, L., and Mantriota, G. "A comparison of the performances of full and half toroidal traction drives", Mech. Mach. Theory, 39(9), pp. 921942 (2004).

27. Moore, T.C. and Lovins, A.B., Vehicle Design Strategies to Meet and Exceed PNGV Goals, The Hypercar Center Rocky Mountain Institute, pp. 1-50, Citeseer (1995).

28. Van Sterkenburg, S., Rietveld, E., Rieck, F., Veenhuizen, B. and Bosma, H. "Analysis of regenerative braking efficiency - A case study of two electric vehicles operating in the Rotterdam area", Int. Conf. Vehicle Power and Propulsion (VPPC), pp. 1-6 (2011).

29. Yeo, H., Hwang, S. and Kim, H. "Regenerative braking algorithm for a hybrid electric vehicle with CVT ratio control", P I Mech. Eng. D-J Aut, 220(11), pp. 1589$1600(2006)$.

30. Del Castillo, J.M. "The analytical expression of the efficiency of planetary gear trains", Mech. Mach. Theory, 37(2), pp. 197-214 (2002).

31. Park, J. and Park, J.H. "Development of equivalent fuel consumption minimization strategy for hybrid electric vehicles", Int. J. of Automot. Techn., 13(5), pp. 835-843 (2012).
32. Shimizu, K. and Seimiya, S. "Test procedure to evaluate fuel consumption of HEVs-universal procedure to secure accuracy", 18th Electric Vehicle Symposium, Berlin, Germany (2001).

33. Delkhosh, M., Foumani, M.S., Boroushaki, M., Ekhtiari, M. and Dehghani, M. "Geometrical optimization of half toroidal continuously variable transmission using particle swarm optimization", Sci. Iran., 18(5), pp. 1126-1132 (2011).

34. Clerc, M., Particle Swarm Optimization, John Wiley \& Sons (2013).

\section{Biographies}

Mojtaba Delkhosh received his BSc, MSc, and PhD degrees in Mechanical Engineering from Sharif University of Technology, Tehran, Iran, in 2009, 2011 and 2016, respectively. His fields of interests are vehicle dynamics, machine design, vibration analysis, power transmission systems, and optimization algorithms.

Mahmoud Saadat Foumani received his $\mathrm{PhD}$ degree in Mechanical Engineering from Sharif University of Technology, Tehran, Iran, in 2002. He was a Faculty member at Semnan University from 2002 to 2006 and is now a faculty member of Sharif University of Technology, Mechanical Engineering Department. He teaches courses in the 'Applied Design Group' at undergraduate and graduate levels. His teaching focuses on mechanical engineering design, vehicle dynamics, chassis design, and advanced mathematics.

Farjad Falahati is BSc student of Applied Mechanical Engineering, Sharif University of Technology, Tehran, Iran. His fields of interest are vehicle dynamics and control strategies of hybrid vehicles. 